\title{
Factors Influencing the Duration of Road Construction Projects in Sri Lanka
}

\author{
Yasas L. Pathiranage and Rangika U. Halwatura
}

\begin{abstract}
This study attempts to reveal the factors influencing the duration of road construction projects in Sri Lanka, and to identify how delays can be mitigated. The emphasis here is limited to study the Contractor's point of view. The main concern of the study is to identify the nature of the population (Road projects in Sri Lanka) using Statistical Inference. The other focusing areas are to identify Main Causes of Delay \& Delay Diversification, and Delay Mitigation. This study defines the Percentage Delay parameter and the Relative Significance Index (RSI) model, which are the new concepts introduced by the author this study.
\end{abstract}

The preliminary data for this research have been collected through a literature review and a questionnaire survey targeted at local contractors of Road Construction. The collected data yields a high reliability coefficient, which is $90 \%$.

This study reveals that the local road construction projects experience $56 \%$ - $88 \%$ of average time overrun compared to the original (planned) project duration. The findings further illustrate that the financial problems of the Owner as well as of the Contractor, is the most influencing factor causing delays in road construction projects in Sri Lanka.

Keywords: Percentage Delay, Relative Significance Index (RSI), Statistical Inference

\section{Introduction}

The time duration of construction projects right from inception to completion is assumed to be of great importance in the construction industry. Further, in many instances it is most cost-effective to complete a project within the shortest possible time [8] [13].

Delays happen in most construction projects, whether simple or complex. Construction delay could be defined as the time overrun either beyond the contract date or beyond the date that the parties agreed upon for delivery of a project [13].

There is a wide range of views on the causes of time delays for engineering and construction projects. Some are attributed to a single party, others can be ascribed to several quarters, and many relate more to systemic faults or deficiencies rather than to a group or groups [9].

Manavazhia and Adhikarib [11] have conducted a survey to investigate material and equipment procurement delays in highway projects in Nepal. Delay in the delivery of materials and equipment to construction sites is often a contributory cause to cost overruns in construction projects in developing countries. An assessment of the causes of the delays and the magnitude of their impact on project costs were also made. The survey method was used in conducting this research involving 22 highway projects. The main causes of material and equipment procurement delays were found to be (in rank order) organizational weaknesses, suppliers' defaults, governmental regulations and transportation delays. However, the actual impact of these delays on project costs was found to be on average, only about $0.5 \%$ of the total budgeted cost of the projects. In the case of materials, delays in the supply of aggregates and equipment were found to occur most frequently.

Noulmanee et al. [12] have investigated causes of delays in highway construction in Thailand and concluded that delays can be caused by all parties involved in projects; however, main causes come from inadequacy of subcontractors, organization that lacks of sufficient

Eng. Y. L. Pathiranage, BSc Eng (Hons), MSc CPM, DCSE, GICE (UK), Aff.M.ASCE, AMIE (STi Lanka). Civil Engineer, Project Management Consultant, and Visiting Lecturer in Civil Engineering.

Eng. (Dr.) R. U. Halwatura, BSc Eng (Hons), PhD, AMIE (Sri Lanka).

Senior Lecturer, Department of Civil Engineering. University of Moratuwa. 
resources, incomplete and unclear drawings and deficiencies between consultants and contractors. The study suggested that delay can be minimized by discussions that lead to understanding.

Hancher and Rowings [9] provided a concise summary of the methodologies used by transportation agencies to establish the contract duration used for highway construction projects, and also provide a schedule guide for field engineers during construction

Ahmed et al. [7] and Alaghbari [1] have identified the following possible factors causing delays in construction projects:

\section{(1) Contractor's responsibility:}

Delay in delivery of materials to site; Shortage of materials on site; Construction mistakes and defective work; Poor skills and experience of labour; Shortage of site labour; Low productivity of labour; Financial problems; Coordination problems with others; Lack of subcontractor's skills; Lack of site contractor's staff; Poor site management; and Equipments and tool shortage on site.

\section{(2) Consultant's responsibility:}

Absence of consultant's site staff; Lack of experience on the part of the consultant; Lack of experience on the part of the consultant's site staff; (managerial and supervisory personnel); Delayed and slow supervision in making decisions; Incomplete documents; and Slowness in giving instructions.

\section{(3) Ozner's responsibility:}

Lack of working knowledge; Slowness in making decisions; Lack of coordination with contractors; Contract modifications (replacement and addition of new work to the project and change in specifications); Financial problems (delayed payments, financial difficulties, and economic problems).

\section{(4) Extemal factors:}

Lack of materials on the market; Lack of equipment and tools on the market; Poor weather conditions; Poor site conditions (location, ground, etc.); Poor economic conditions (currency, inflation rate, etc.); Changes in laws and regulations; Transportation delays; External work due to public agencies (roads, utilities and public services).

Most of road construction projects in Sri Lanka experience larger delays, and hence it adversely affects the economy in many ways. Further, this has been identified as a socio-economic problem, and therefore an urgent rectification is required.

This study attempts to reveal the factors influencing the duration of road construction projects in Sri Lanka, and to identify how delays can be mitigated. Further, a prediction about the nature of the population (Road projects in Sri Lanka) is done through analysis of a random sample. The emphasis here is limited to the Contractor's point of view. As the data collection is done via a questionnaire survey, the accuracy of the findings and as well as the analysis merely would depend on the quality of the responses.

The preliminary data for this research were collected through a literature review and a questionnaire survey targeted at local contractors of road construction.

The main objectives of this study are to:

- Identify the nature of the Population (Road projects in Sri Lanka) using Statistical Inference

- Identify the Main Causes of Delay \& Delay Diversification

- Identify the ways of Delay Mitigation

\section{Methodology of Study}

The impacts and causes of project delays were first examined and identified through a relevant international literature review and by conducting a pilot study that sought advice from experienced highway construction practitioners (specialists) in Sri Lanka. The basic purpose of the pilot study was to verify the completeness of the questionnaire in capturing the factors relevant to Sri Lankan situation.

A questionnaire was developed based on Ahmed et al. [7] and Alaghbari [1] to assess the perceptions of contractors on the Percentage Delay and the Relative Significance Index of factors influencing the duration of road construction projects in Sri Lanka. All the 
practitioners (specialists) agreed that the questionnaire, which based on Ahmed et al. [7] and Alaghbari [1], was sufficient to capture the causes of delays in Sri Lankan road construction sector.

The questionnaire was divided into three parts. The first part requested Background Information about the respondents. The second part of the questionnaire captured the Project Infornation in order to estimate the Percentage Delay. The third part of the questionnaire focused on Causes of Road Construction Delay. The respondents were asked to indicate their response based on 31 well-recognized construction delay factors (causes of delay). These causes were categorized into the four major groups of Contractor's responsibility, Consultant's responsibility, Owner's responsibility, and External factors.

\subsection{Justification of Sample Size and Reliability of Data}

As per the Central Limit Theorem, when the Sample Size approaches 30, the Distribution of Sample Mean is approximately Normal in spite of the Distribution of Population [2] [3] [4] [6] [14]. Therefore, in this study a Random Sample of 30 projects has been considered for the analysis in order to predict the nature of the Population (Confidence Interval for Population Mean).

The reliability of a measure illustrates its stability and consistency, which assists in evaluating the "goodness" of a measure. The reliability coefficient obtained with the repetition of an identical measure on a second occasion is called test-retest reliability [5]. The reliability and stability of the measure would increase with a greater reliability coefficient. In this regard, the same set of blanked questionnaires were resent with a self stamped return envelope to 6 respondents $(20 \%)$ who had completed and returned their questionnaire previously, in order to test the reliability. A total of 5 completed questionnaires were eventually received in the resending process. After crosschecking the results, $90 \%$ of the answers were the same as in the previous survey, thus yielding a high reliability coefficient $(90 \%)$. The data, therefore, were considered to be reliable. It is also noted that the demographic statistics about the respondents (Table 1) suggest sufficient exposure to make the information acquired reliable, and thus the opinions are thought to reflect the real situation in the prevailing context of the road construction projects in Sri Lanka.

\subsection{Percentage Delay}

In this study, we introduce a new parameter called Percentage Delay $\left(\mathrm{d}_{i}\right)$ as a parameter of the Magnitude of Delay, which yields from the equation,

$$
d_{i}=\frac{t_{\text {Actually Elapsed }}-t_{\text {Planned }}}{t_{\text {Planned }}}
$$

Where,

$$
\begin{aligned}
& t_{\text {Actually Elapsed }}=\text { Actual Time Elapsed for the Completion } \\
& t_{\text {Planned }}=\text { Planned Project Duration }
\end{aligned}
$$

$\mathrm{d}_{i}$ is a measure of actual impact of the delay with respect to the time for a particular project. Further, in practical perspective, $d_{i}$ is the time overrun compared to the original (planned) project duration.

In this study, a random sample of 30 projects has been examined and then the Statistical Inference is used to predict the nature of the Population (Road Construction Projects in Sri Lanka).

\subsection{Confidence Interval for Population Mean of Percentage Delay}

As per the Central Limit Theorem [2] [3] [4] [6] [14], $(1-\alpha)$ Confidence Interval for Population Mean $(\mu)$ of Percentage Delay $\left(\mathrm{d}_{i}\right)$ is,

Where,

$$
\mu_{d_{i}}=\left(\bar{x}-c \frac{\sigma}{\sqrt{n}}, \bar{x}+c \frac{\sigma}{\sqrt{n}}\right)
$$

$\bar{x}=$ Sample Mean $=\frac{\sum_{i=1}^{n} d_{i}}{n}$

$\sigma=s=$ Sample Standard Deviation $=\sqrt{\frac{\sum_{i=1}^{n} d_{t}^{2}}{n}-\left(\frac{\sum_{i=1}^{n} d_{i}}{n}\right)^{2}}$

$c=1.96$ for $95 \%$ Confidence, and $n=$ Sample Size $=30$ in this case

\section{$2.4 \quad$ Relative Importance Index (RII)}

Kometa et al. [10] used the Relative Importance Index (RII) method to determine the relative importance of various causes of delays. The five-point scale ranged from 1 (not significant) to 5 (extremely significant) was adopted and transformed to relative importance indices (RII) for each cause as follows: 


$$
R I I=\frac{\sum W}{A^{*} N}
$$

Where,

" $\mathbf{W}$ " is the weighting given to each factor by the respondents (ranging from 1 to 5 ),

" $A$ " is the highest weight (i.e. 5 in this case), and

"N" is the total number of respondents.

The RII value had a range from 0 to 1 , higher the value of RII, more important was the cause or effect of delays. The RII was used to rank the different causes.

\section{$2.5 \quad$ Relative Significance Index (RSI)}

The Relative Importance Index (RII) method suggested by Kometa et al. [10] had focused merely on the weighting given by the respondents (frequency) despite the amount of delay (magnitude) that the relevant project was undergone. That means, RII model assumes, all the projects are undergone the similar impact in the context of amount of delay, when the delays are ranked. But, in real practice we know that most frequent delay causes may not always be the most significance delay causes, in the context of the actual impact.

In order to supplement the above drawback, more sophisticated method (a new equation) has been introduced in this study with the new input parameter of Percentage Delay (a parameter of the Magnitude of Delay) in order to reveal the Relative Significance of the various causes of delays. The five-point scale ranged from 1 (not significant) to 5 (extremely significant) was adopted and transformed to Relative Significance Indices (RSI) for each cause as follows:

$$
R S I=\frac{\sum_{i=1}^{n}\left(W_{i}^{*} d_{i}\right)}{A^{*} \sum_{i=1}^{n} d_{i}}
$$

Where,

" $\mathbf{W}_{i}$ " is the weighting given to the particular cause for $i^{\text {th }}$ project by the respondents (ranging from 1 to 5),

" $\mathrm{d}_{i}$ " is the Percentage Delay of $i^{\text {th }}$ project,

$$
d_{i}=\frac{t_{\text {Actuaslyy Elapsed }}-t_{\text {Plamned }}}{t_{\text {Planned }}}
$$

" $\mathbf{A}$ " is the highest weight (i.e. 5 in this case), and

" $n$ " is the total number of projects (number of respondents, i.e. 30 in this case).

The RSI value had a range from 0 to 1 , higher the value of RSI, more significant is the cause or effect of delays. The RSI was used to Rank (R) the different causes. These rankings made it possible to reveal the Relative Significance of the Delay Factors as perceived by the Contractors of Road Construction in Sri Lanka.

\section{Analysis}

Analysis of the following items is illustrated with regard to the survey carried out based on the duration of road construction projects in Sri Lanka that targeted at the local road construction Contractors.

- Respondents' Background with respect to Education, Occupational level, and Number of years working experience

- Confidence Interval for Population Mean of Percentage Delay

- Relative Significance Index (RSI)

- Ranking of delay factors based on RSI

Finally, based on the analysis, the results will be discussed upon the factors influencing the duration of road construction projects in Sri Lanka.

\subsection{Respondents' Background}

In this study, 30 respondents were participated representing distinct road construction projects. Their Background was analysed with respect to the Education, the Occupational level, and the Number of years of working experience. The result were analysed using MS-Excel Statistical Package.

The Table 1 below illustrates the detailed analysis of Respondents' Background, which was analysed with respect to the Education, the Occupational level, and the Number of years of working experience.

With respect to their education; $\mathbf{4 0} \%$ of them had a Diploma, $53 \%$ of them had a Degree, and $7 \%$ of them had Post graduate qualifications. 
With respect to their occupational level; $20 \%$ of them operated as Non-executives, $50 \%$ of them operated as Executives, and $30 \%$ of them operated as Managerial capacities.

With respect to their number of years of working experience; $13 \%$ of them had Less than 2 years, $17 \%$ of them had 2-5 years, $40 \%$ of them had 6-10 years, and $30 \%$ of them had More than 10 years of working experience.

These demographic statistics about the respondents suggest sufficient exposure to make the information acquired reliable, and thus the opinions are thought to reflect the real situation in the prevailing context of the road construction projects in Sri Lanka.
Table 1 - Analysis of Respondents' Background

\begin{tabular}{|c|c|c|c|c|c|c|c|c|c|c|}
\hline Percentage & 亏ें & శ్రి & $\div$ & ;े & 产 & : & 癸 & $\stackrel{20}{z}$ & & : \\
\hline Total & $\cong$ & 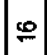 & $\sim$ & 0 & $\stackrel{2}{2}$ & का & 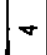 & in & $\simeq$ & $\sigma$ \\
\hline
\end{tabular}

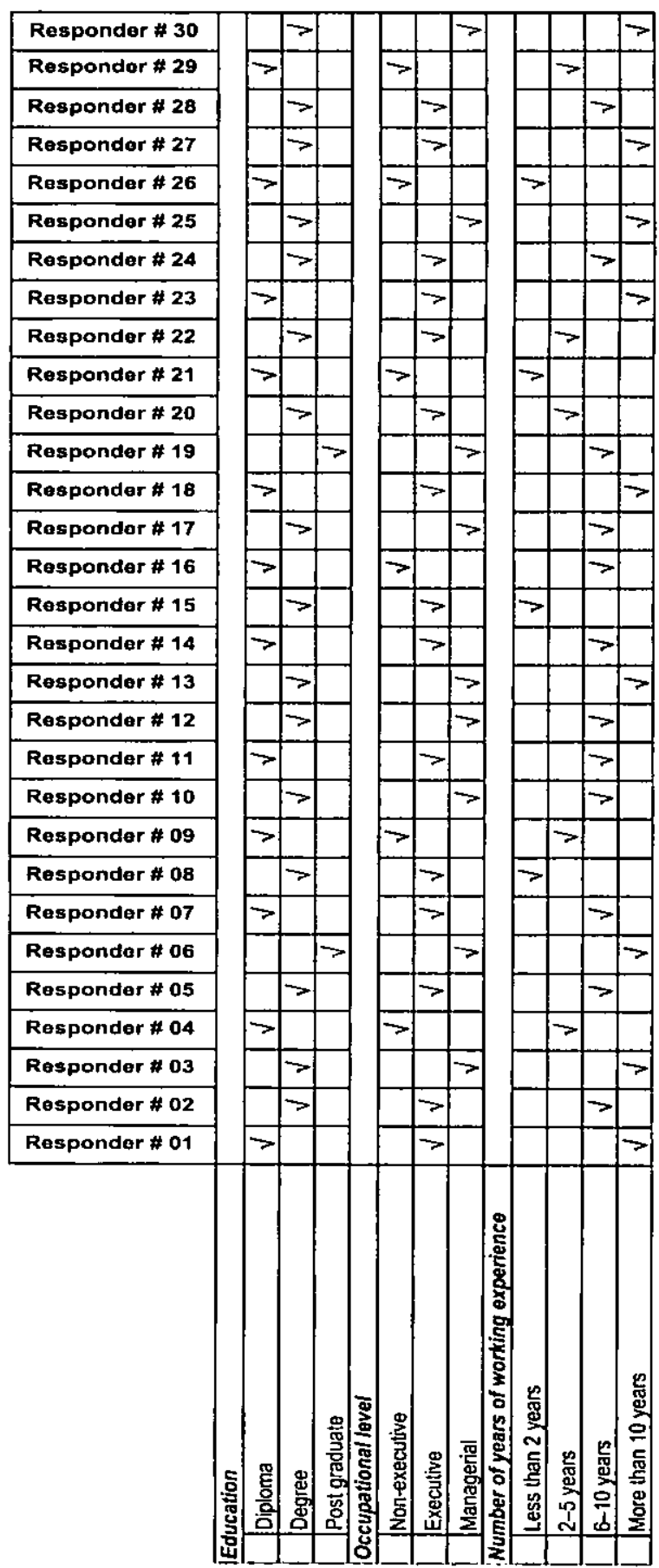




\subsection{Confidence Interval for Population} Mean of Percentage Delay

As per the Equation 2, $(1-\alpha)$ Confidence Interval for Population Mean $(\mu)$ of Percentage Delay $\left(\mathrm{d}_{\mathrm{i}}\right)$ is,

$$
\mu_{d_{t}}=\left(\bar{x}-c \frac{\sigma}{\sqrt{n}}, \bar{x}+c \frac{\sigma}{\sqrt{n}}\right)
$$

Let's calculate the elementary items as follows for $n=$ Sample Size $=30$,

$\bar{x}=$ Sample Mean $=\frac{\sum_{i=1}^{L} d_{t}}{n}=\frac{21.69}{30}=0.72$

$\sigma=s=$ Sumple Standard Deviation $=\sqrt{\frac{\sum_{i=1}^{n} d_{i}^{2}}{n}-\left(\frac{\sum_{i=1}^{n} d_{i}}{n}\right)^{2}}=\sqrt{\frac{21.64}{30}-\left(\frac{21.69}{30}\right)^{2}}=0.45$

$c=1.96$ for $95 \%$ Confidence Interval(Significance Level $\alpha=0.05$ )

Therefore,

$$
\begin{aligned}
& \mu_{d_{1}}=\left(0.72-1.96 * \frac{0.45}{\sqrt{30}}, 0.72+1.96 * \frac{0.45}{\sqrt{30}}\right) \\
& \mu_{d_{1}}=(0.56,0.88)
\end{aligned}
$$

Thus, it can be concluded that the mean Percentage Delay lies between 0.56 and 0.88 with respect to the road construction projects in Sri Lanka (with 95\% Confidence). This means that the local road construction projects are experienced $56 \%-88 \%$ of average time overrun compared to the original (planned) project duration.

3.3 Relative Significance Index (RSI) and Ranking of Delay Factors

As per the Equation 4, Relative Significance Index (RSI) is given by,

$$
R S I=\frac{\sum_{i=1}^{n}\left(W_{i}^{*} d_{i}\right)}{A^{*} \sum_{i=1}^{n} d_{i}}
$$

Let's calculate the elementary items as follows,

" $W_{i}$ " is the weighting given to the particular cause for $i^{\text {th }}$ project by the respondents (ranging from 1 to 5 ),

" $\mathrm{d}_{i}$ " is the Percentage Delay of $i^{\text {th }}$ project,

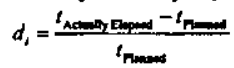

" $A$ " is the highest weight (i.e. 5 in this case), and

" $n$ " is the total number of projects (number of respondents i.e. 30 in this case).

The output of the survey carried out was analysed using MS-Excel Statistical Package. The Table 2 and 3 below illustrate the detailed analysis of Relative Significance Index (RSI) and Rank (Group \& Overall) of various Causes of Delays (Delay Factors). Further, the Proportionate Significances of Delay Factors were identified via Weightages (Group \& Overall). After that, Most Significance Delay Factors were highlighted. 
Table 2 - Analysis of Relative Significance Index (RSI)

Road Construction Deday Factors

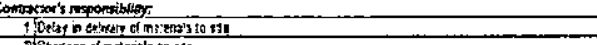

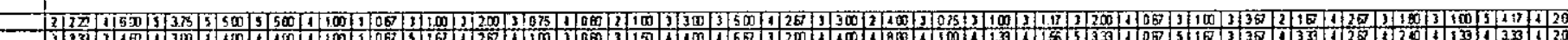

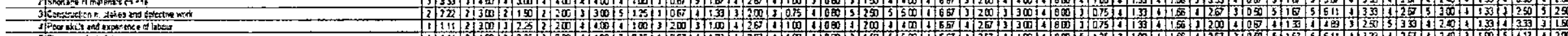

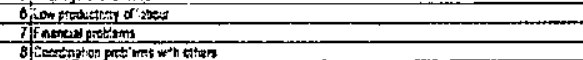

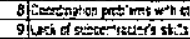

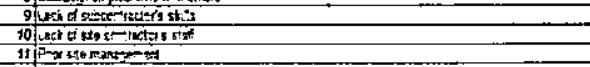

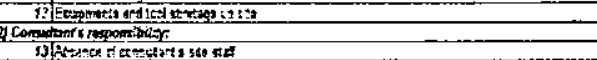

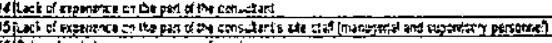

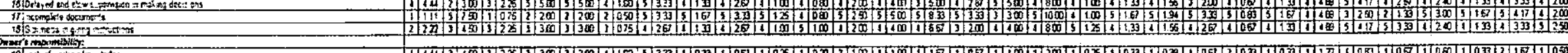

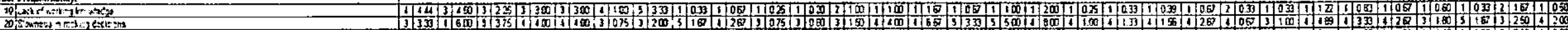

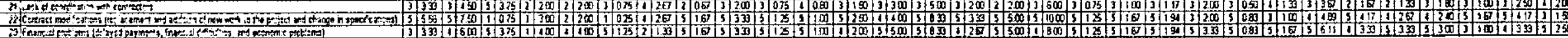

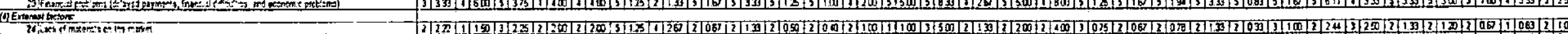

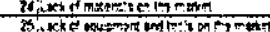

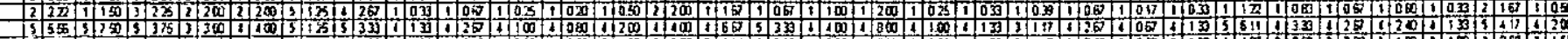

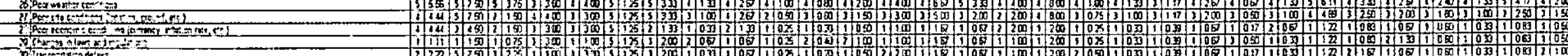


Table 3 - Ranking of Delay Factors based on

Relative Significance Index (RSI)
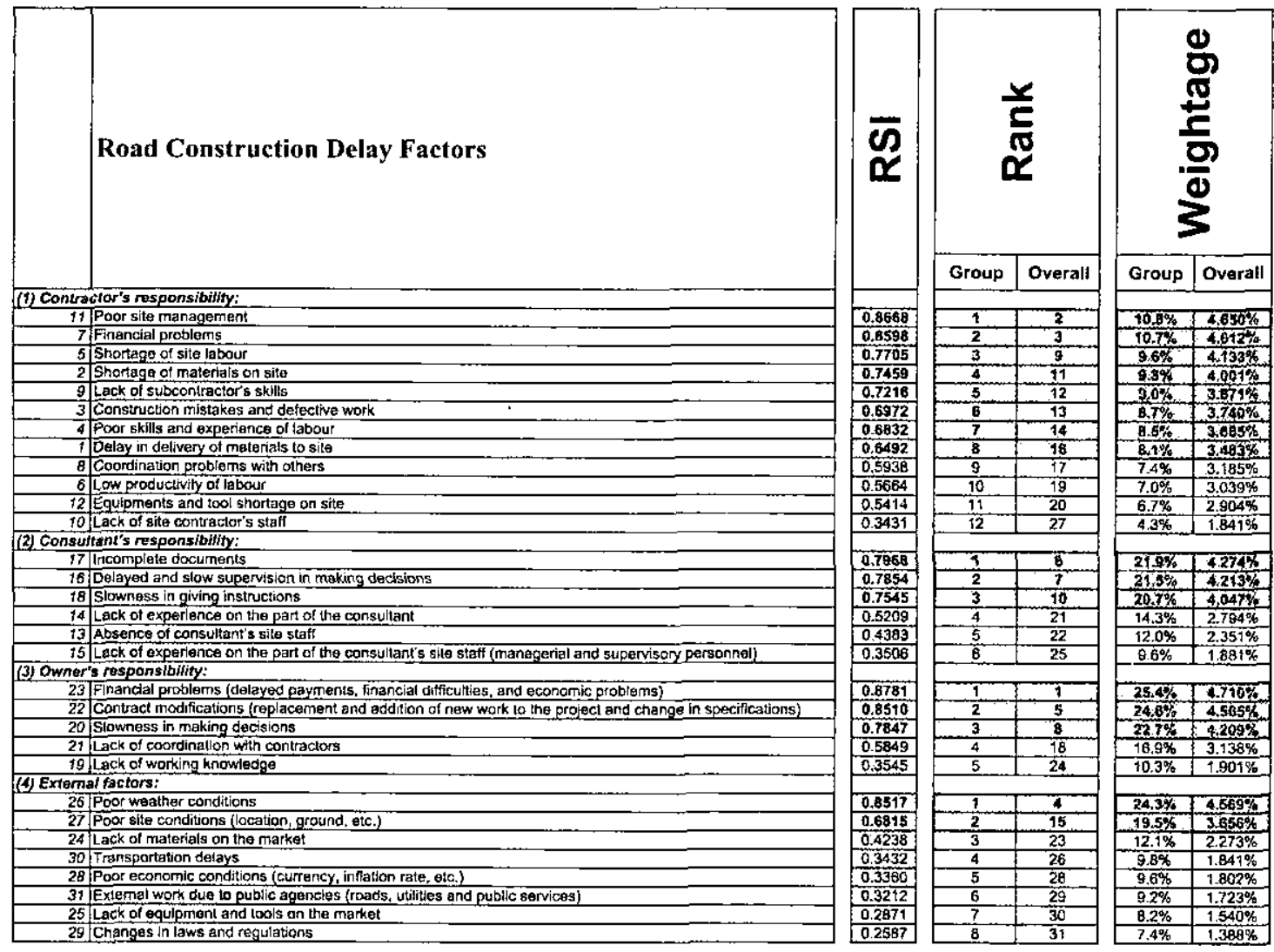

The different groups (Contractor, Consultant, Owner, and External factors) were further analysed upon the Group Rank, and the Proportionate Significances of Delay Factors were depicted in Figure 1, 2, 3, and 4 respectively.
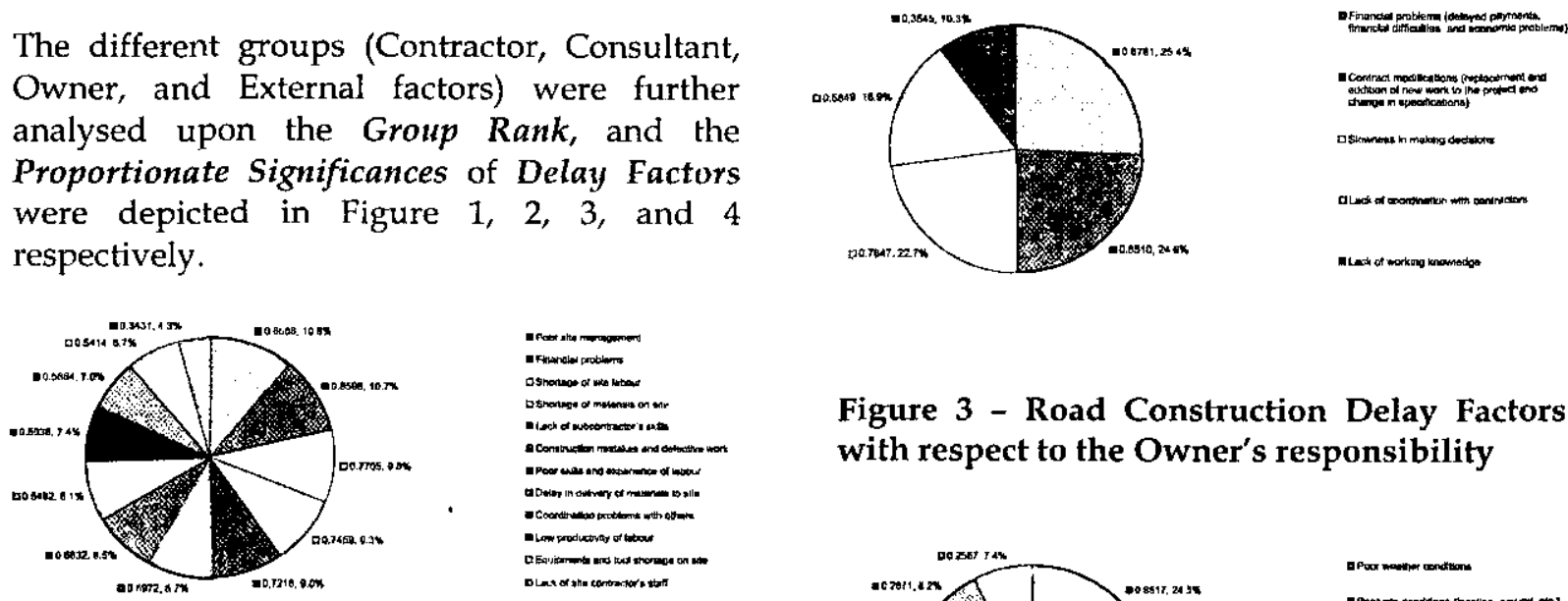

Figure 1 - Road Construction Delay Factors with respect to the Contractor's responsibility
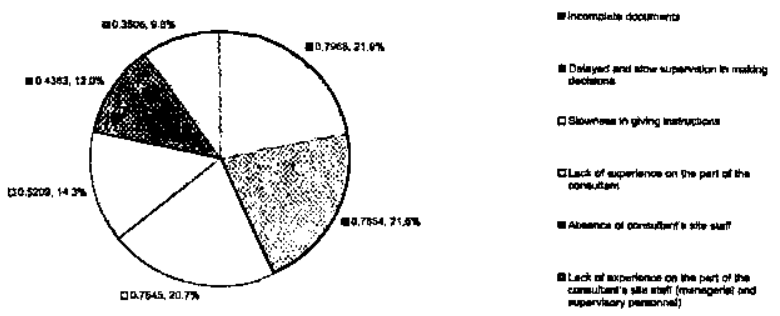

Figure 2 - Road Construction Delay Factors with respect to the Consultant's responsibility

Figure 3 - Road Construction Delay Factors with respect to the Owner's responsibility
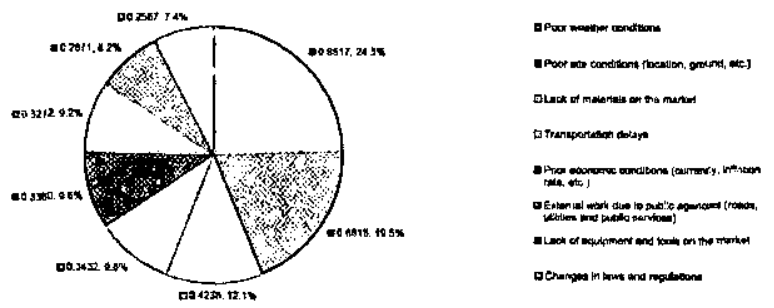

Figure 4 - Road Construction Delay Factors with respect to the External factors

Most significant Contractor's responsibilities were: Poor site management (RSI $=0.8668, \mathrm{GW}$ $=10.8 \%$, OW $=4.650 \%$, Financial problems $(\mathrm{RSI}=0.8598, \mathrm{GW}=10.7 \%, \mathrm{OW}=4.612 \%)$, Shortage of site labour $(\mathrm{RSI}=0.7705, \mathrm{GW}=$ 
$9.6 \%$, OW $=4.133 \%$, Shortage of materials on site $(\mathrm{RSI}=0.7459, \mathrm{GW}=9.3 \%$, OW $=4.001 \%$ ), Lack of subcontractor's skills (RSI $=0.7216$, $\mathrm{GW}=9.0 \%$, OW $=3.871 \%)$, Construction mistakes and defective work (RSI $=0.6972, \mathrm{GW}$ $=8.7 \%, \mathrm{OW}=3.740 \%)$, Poor skills and experience of labour (RSI $=0.6832, \mathrm{GW}=8.5 \%$, $\mathrm{OW}=3.665 \%$ ), and Delay in delivery of materials to site $(\mathrm{RSI}=0.6492, \mathrm{GW}=8.1 \%$, OW $=3.483 \%$ ).

Most significant Consultant's responsibilities were: Incomplete documents (RSI $=0.7968, \mathrm{GW}$ $=21.9 \%$, OW $=4.274 \%$ ), Delayed and slow supervision in making decisions (RSI $=0.7854$, GW $=21.5 \%$, OW $=4.213 \%$, and Slowness in giving instructions (RSI $=0.7545, \mathrm{GW}=20.7 \%$, OW $=4.047 \%$ ).

Most significant Ozner's responsibilities were: Financial problems (delayed payments, financial difficulties, and economic problems) (RSI $=0.8781, \mathrm{GW}=25.4 \%$, OW $=4.710 \%$ ), Contract modifications (replacement and addition of new work to the project and change in specifications) (RSI $=0.8510, \mathrm{GW}=24.6 \%$, $\mathrm{OW}=4.565 \%)$, and Slowness in making decisions $(\mathrm{RSI}=0.7847, \mathrm{GW}=22.7 \%, \mathrm{OW}=$ $4.209 \%)$.

Table 4 - Overall Ranking of Delay Factors based on Relative Significance Index (RSI)
Most significant External factors were: Poor weather conditions $(\mathrm{RSI}=0.8517, \mathrm{GW}=24.3 \%$, OW $=4.569 \%)$, and Poor site conditions (location, ground, etc.) $(\mathrm{RSI}=0.6815, \mathrm{GW}=$ $19.5 \%$, OW $=3.656 \%$ ).

Finally, in Table 4, all the Causes of Delays were again ranked upon the Overall Rank, and the relevant responsibilities of each cause (Delay Factor) were highlighted. The Proportionate Significances of Road Construction Delay Factors for all 4 groups were identified via Weightages (Overall), and depicted in Figure 9.

Therefore the Factors Influencing the Duration of Road Construction Projects in Sri Lanka, can be tabulated as in Table 5 .

According to the above findings, it is obvious that the Contractor is the most responsible party for the road construction delays in Sri Lanka, compared to the Consultant and the Owner. However, the responsibility of Owner is perceived important than the Consultant as per the revealed facts. External factors have also contributed to the delays, but not at a very significant level:

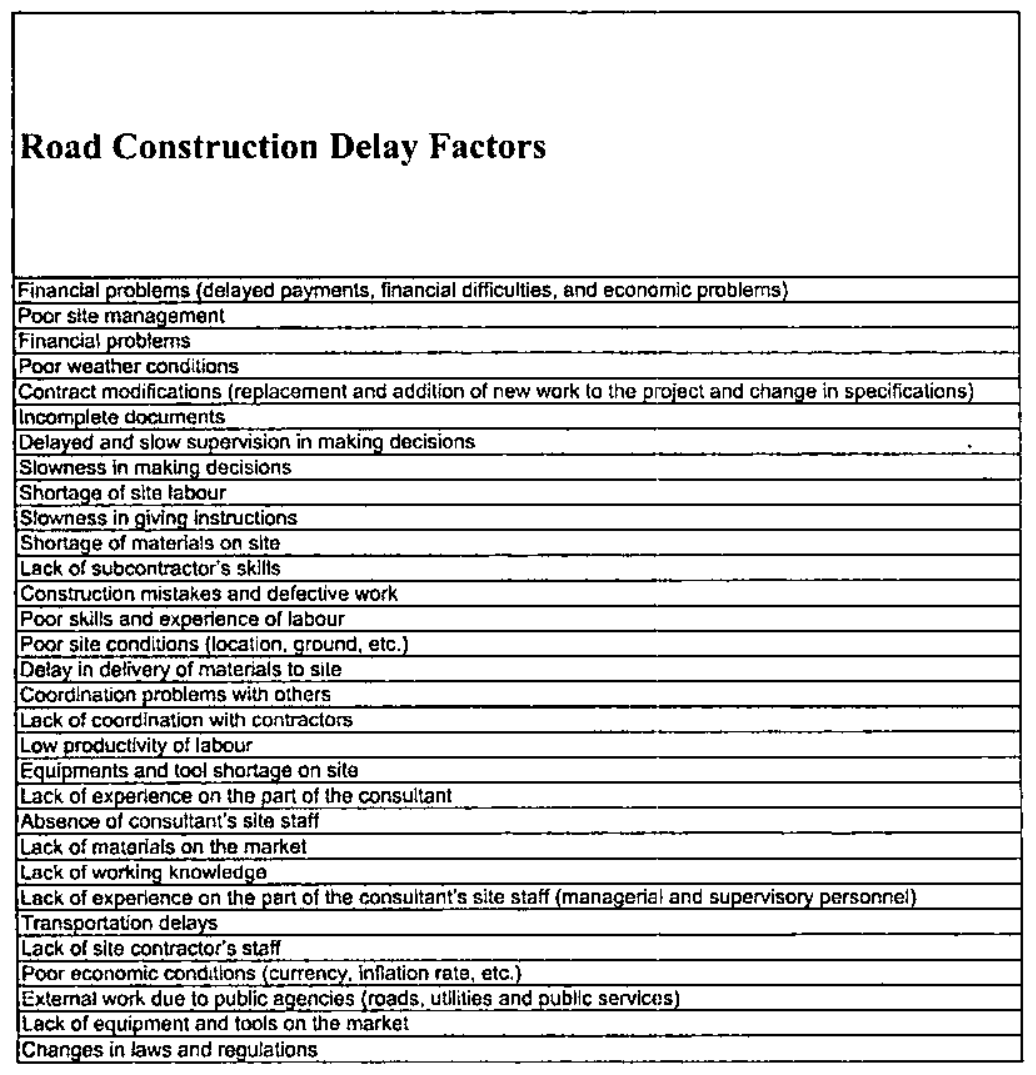

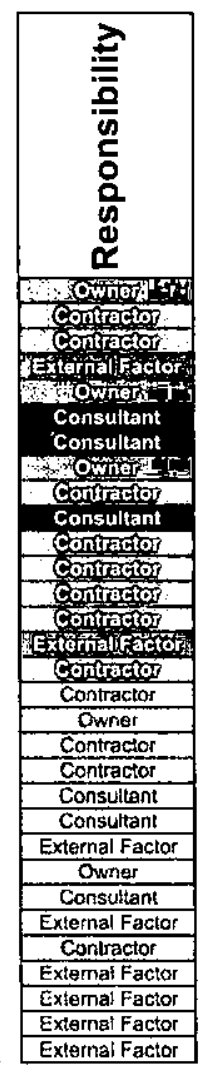




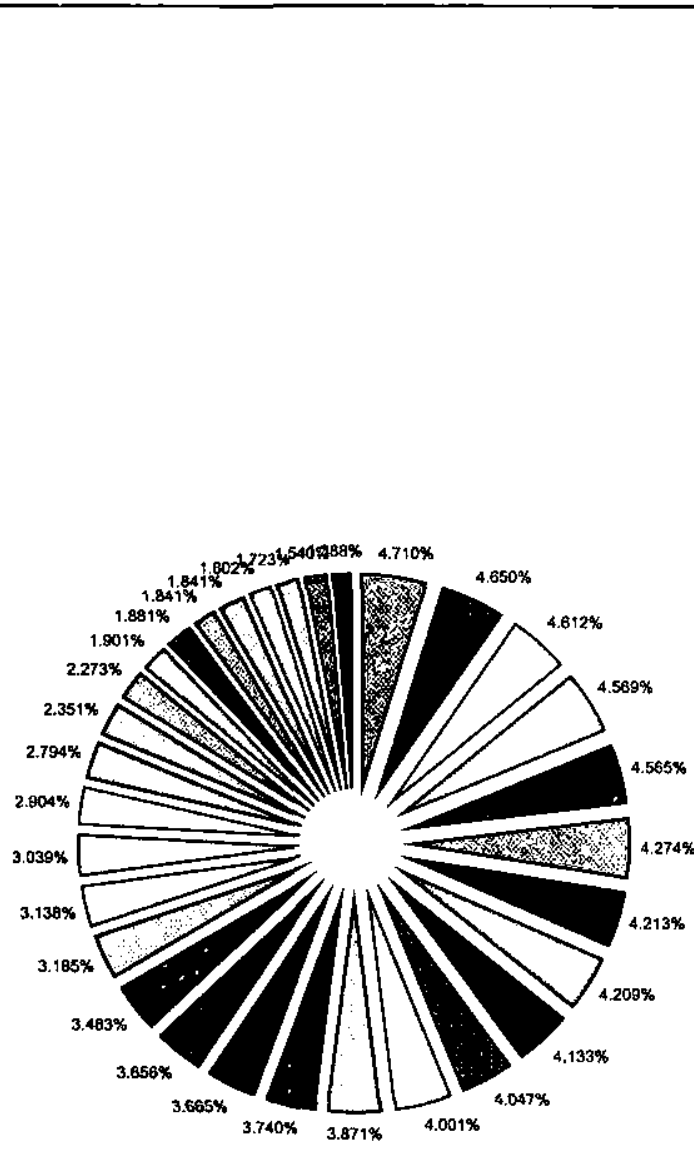

Figure 5 - Road Construction Delay Factors (for all 4 cases)

QFinancial probiems (delayed payments, financial difficulties, and economic problems)

- Poor sile management

口Financial probtems

口Poor weather conditions

- Contract modiflcations (reptacement and addition of new work to the project and change in specifications) [Incomplete documents

- Delayed and slow supervision in making decisions

clowness in making decisions

Shortage of site labour

ه Slowness in giving instructions

DShortage of materials on site

QLack of subcontractor's skills

a Construction mistakes and defective work

Poor skills and experience of labour

a Poor site condlitions (location, ground, etc.)

Delay in delivery of materials to site

口coordination problems with others

DLack of coordination with contractors

DLow productivity of labour

DEquipments and tool shortage on slte

- Lack of experience on the part of the consultant

口Absence of consultant's site staff

DLack of materials on the market

DLack of working knowledge

R Lack of experience on the part of the consultant's site staff (managerial and supervisory personnel)

-Transportation delays

QLack of site contractor's staff

apoor econornic conditions (currency, inflation rate, etc.)

DExternal work due to public agencies (roads, utitities and public services)

- Lack of equipment and tools on the market

WChanges in laws and regulations

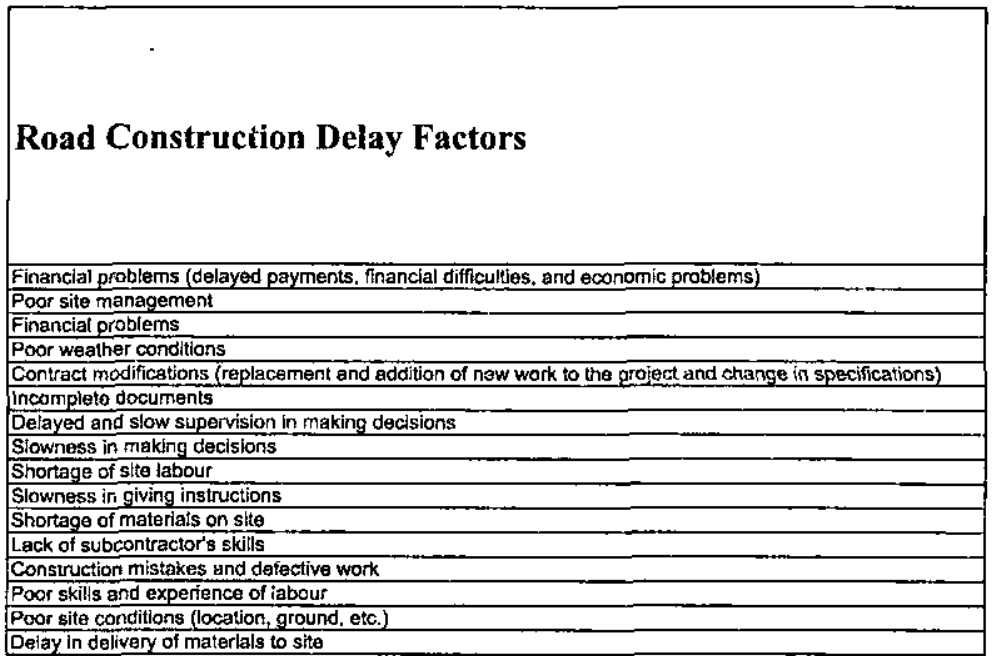
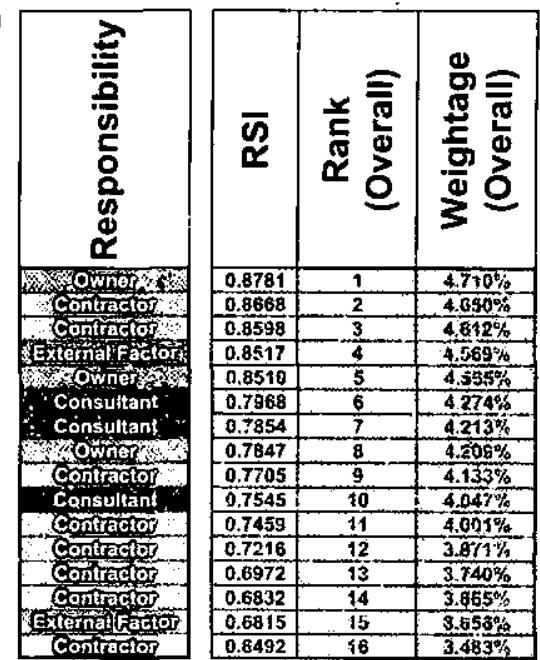

Table 5 - Factors Influencing the Duration of Road Construction Projects in Sri Lanka 


\section{Discussion}

This study focused on the delays of road construction projects, and a formal attempt made to reveal the factors influencing the duration of road construction projects in Sri Lanka from Contractor's perspective.

The data for the analysis were collected via a survey targeted at the local road construction Contractors. The collected data yielded a reliability coefficient of $90 \%$.

This study found that the local road construction projects are experienced $56 \%-88$ $\%$ of average time overrun compared to the original (planned) project duration. This finding was obtained from statistical inference of percentage delay, which is a new parameter introduced in this study.

Another new concept that has been introduced in this study is the Relative Significance Index (RSI). The RSI is mainly adhered with the input parameters of Respondent's Weighting and Percentage Delay in order to measure the relative significance of Delay Factors. The results of the analysis show that, from a total of 31 variables (Delay Factors) examined, separated into four categories by the responsibility, the major factors causing delay in road construction projects are factors due to the Contractor, followed by factors due to the Owner, factors due to the Consultant, and finally factors due to External Factors.

According to the findings, the financial problems of the Owner as well as of the Contractor, is the most influencing factor in causing delay in road construction projects in Sri Lanka. Poor site management by the Contractor, followed by poor weather conditions that is an External Factor, contract modifications by the Owner, incomplete documents, delayed and slow supervision in making decisions and giving instructions by both the Consultant and the Owner appeared to be the next critical factors in causing delays in local road constructions. Further, the responsibilities of the Contractor such as, shortage of site labour and materials, lack of subcontractor's skills, construction mistakes and defective work, poor skills and experience of labour, and finally delay in delivery of materials to site were revealed as the factors with significant probability of causing delays.
Therefore, a stern emphasis has to be drawn for the following focusing areas in order to mitigate the effects of delays in road construction projects in Sri Lanka.

\subsection{Financial problems}

Cash flow problems / financial difficulties, and insufficient resources by the contractors can be eliminated by a good practice in the contractor selection process. It is therefore essential to take into account not only on the lowest bidding price, but also the previous working experience and reputation of the contractors and subcontractors.

Proper costing is essential in every road construction project. The initial cost estimates shall be as accurate as possible. This would allow Owners to ensure that the required funds for executing the project are sourced on time and made available when required. Cost and value engineering principles must be applied at all stages of the project.

Financial Support as well as Technical Support is a very necessary and urgent step for road construction investments, since the results of the analysis show that financial problems are the most influencing factor causing delay. Further, Capacity Building is essential for sustainable development. Governments shall set up deliberate schemes that can help local contractors build their capacity by availing them credit facilities. This would ensure adequate equipment availability.

Delayed payments due to complex financial processes in Owner organizations would cause financial difficulties to contractors, and consequently cause time overruns. Therefore, Owners shall ensure that they have sufficient funds available for the projects before commissioning.

\subsection{Poor site management}

Contractors shall have able site managers for plan their work properly, and for the smooth execution of work. During the execution stage of the project, site managers shall ensure that the contractual obligations are dealt with diligently within the stipulated Cost, Time, and the Quality of Works.

Since there are many parties (Owner, Consultant, Contractor, and Sub-contractors etc.) involved in a project, the communication 
between the parties is very crucial for the success of the project. Any problem with communication can lead to severe misunderstanding and hence delays in the execution of the project. Therefore, proper communication channels between the various parties shall be established during the planning stage.

Effective communication can alleviate most of the factors that cause delays in road construction projects. Owners ought to promote team building communication processes. Site managers need to deal with all project issues objectively and ensure that all communication is project issue based.

\subsection{Poor weather conditions}

The projects earmarked for construction shall be properly planned and timed in such a way that most of the works can be executed in seasons of clement weather. Further, the Contractors have to expedite and complete the works as much as possible within that period since the weather conditions in Sri Lanka may not remain the same for a long period.

\subsection{Contract modifications}

Excessive change orders (Contract modifications) have a tremendous effect on the financial performance of a road construction project. According to many experts, the average cost of change orders on road construction, as a percentage of the original project budget, is $5 \%$ $10 \%$. Therefore, Owners shall draw more emphasis in this regard before initiate a modification in the contract. However, contingency allowances may be incorporated for inevitable variations.

For any project, scope needs to be well defined from inception to completion. Scope changes often lead to claims, and sometimes to disruption of work due to inadequate analysis of the project in its initial stages. Further, it shall be borne in mind that contractors tend to claim over the price variations so as to cover up for any short falls in their initial bids. This implies that the variations that result from scope enlargements are more costly hence compound cost escalation. Effective scope definition is therefore indispensable for a successful project delivery.
4.5 Incomplete documents / Slowness in making decisions

While drawing the contract between the Owner and Contractor, the Consultant must conspicuously include items such as duration of the contract, mechanism to solve disputes including extra work and additional works, mechanism to assess the causes of delay if there are any, and risk management plans etc.

Consultants shall prepare and approve drawings on time according to a set schedule, and shall monitor the work closely by making inspections at appropriate times.

Consultants shall be flexible enough in evaluating contractor's works so that intuitive compromising to be assured between the cost and the quality.

Owners must make quick decisions to solve any problem that arise during the execution.

\subsection{Shortage of site labour and materials}

The quality and quantity of labour supply can have major impacts on the progress of road construction projects. Therefore, Contractors shall assign enough number of capable labours on time, and shall motivate them to improve productivity.

Contractors shall draw more emphasis on time delivery of materials to the site, as in many local road projects the works are been held up due to materials shortages.

\subsection{Lack of subcontractor's skills / Poor skills and experience of labour}

Manpower, at both the technical and the managerial levels, shall have their own knowledge updated by continuous professional development schemes.

Effective project implementation requires competent personnel. This would minimise errors, poor supervision and enhance coordination on sites.

Wherever possible, construction professionals need to have experience and qualifications in Construction Project Management so that they can effectively utilise the project management tools that are available. 
Contractors shall not take up the job in which they do not have sufficient expertise.

\subsection{Construction mistakes and defective work}

The mistakes during the construction stage can be due to accidents, inadequate planning, or miscommunication between the parties. Whatever the reason, mistakes can have significant impacts on the project progress while the redoing work involves additional expenses. Therefore, it is worthwhile for Contractors to draw stern emphasis in order to minimise the probable mistakes that arise during the construction stage.

\subsection{Poor site conditions}

Although natural ground conditions sometimes cannot be thoroughly predictable, a sound preparations and investigations are required before commencement of construction in order to reduce the impact of any unforeseen ground conditions.

\section{Conclusions}

This study revealed that the local road construction projects experience $56 \%-88 \%$ of average time overrun compared to the original (planned) project duration. The findings further illustrated that the financial problems of the Owner as well as of the Contractor, is the most influencing factor causing delays in road construction projects in Sri Lanka.

\section{Recommendations}

Based on the findings and discussions of the study, the following recommendations can be suggested in order to mitigate the effects of delays in road construction projects in Sri Lanka.

- Owners and consultants shall exercise good practices in contractor selection process

- Contractors and owners shall perform proper costing, and cost \& value engineering principles must be applied at all stages of the project
- Contractors shall draw more emphasis on proper site management and effective communication between the parties

- Contractors shall assign enough number of capable labours on time, and shall draw more emphasis on time delivery of materials to the site

- Contractors shall draw stern emphasis for minimise the probable construction mistakes and for minimise the consequent redoing work

- Weather is something beyond control; but proper work planning by contractors shall ensure to execute most of the works in seasons of clement weather

- Proper scope definition is a must; owners and consultants shall draw more emphasis before initiate a modification in the contract, and however contingency allowances may be incorporated for inevitable variations

- Consultants shall draw constructive approach towards disputes and ambiguities of the contract, and shall prepare and approve drawings and other relevant documents on time according to a set schedule

- Owners and consultants shall make quick decisions to solve any problem that arise during the execution; intuitive compromising shall be assured between the cost and the quality

- Sound preparations and investigations are required before commencement of construction in order to reduce the impact of any unforeseen ground conditions

- Manpower at both the technical and the managerial levels shall have their own knowledge and experience updated by continuous professional development schemes 
- Governments shall set up deliberate schemes for capacity building (financial support) of owners and contractors

\section{Implications for Future Research and Developments}

RSI model, which is the new concept introduced in this study, can be utilised for any kind of Delay Analysis in order to measure the Relative Significances of Delay Factors (Causes of Delay).

The focused area in this research can be broaden up to all the Civil Engineering Projects with the perspectives of Contractors, Consultants, and Owners.

Moreover, similar studies can be performed for the different parts of the world in order to investigate the prevailing trends of construction delay in global context.

Further, a Construction Time Delay Model for Civil Engineering Industry can be developed with the comprehensive investigation of such trends.

\section{References}

1. Alaghbari, W.A.M., "Factors affecting construction speed of industrialized systems in Malaysia", Master's thesis, University Putra Malaysia, Serdang, 2005.

2. Dowdy, S., Wearden, S., "Statistics for Research", Second Edition, John Wiley \& Sons, New York, 1985.

3. George, S.W., William, C.G., "Statistical Methods", Eighth Edition, Iowa State University Press, 1989.

4. Lapin, L.L., "Probability and Statistics for Modern Engineering", Second Edition, Waveland Press Inc., 1998.

5. Sekaran, U., "Research methods for business", Second Edition, John Wiley \& Sons, New York, 1992.
6. Walpole, R.E., Myers, R.H., Myers, S.L., Ye, K., "Probability \& Statistics for Engineers \& Scientists", Eighth Edition, Pearson Education Inc., 2007.

7. Ahmed, S.M., Azhar, S., Kappagntula, P., Gollapudil, D., "Delays in construction: a brief study of the Florida construction industry", Proceedings of the 39th Annual ASC Conference, Clemson University, Clemson, SC, pp 257-266, 2003.

8. Al-Moumani, H.A., "Construction delay: a quantitative analysis", International Journal of Project Management, Vol. 18, pp 51-59, 2000.

9. Hancher, D.E., Rowings, I.E., "Setting highway construction contract duration", Journal of Construction Engineering and Management, ASCE, Vol. 107 No. 2, pp 169-179, 1981.

10. Kometa, S.T., Olomolaiye, P.O., Harris, F.C., "Attributes of UK construction clients influencing project consultants' performance", Construction Management Economics, Vol.12, pp 433-443, 1994.

11. Manavazhia, M.R., Adhikarib, D.K., "Material and equipment procurement delays in highway projects in Nepal", International Journal of Project Management, Vol. 20, pp 627-632, 2002.

12. Noulmanee, A., Wachirathamrojn, J., Tantichattanont, P., Sittivijan, P., "Internal causes of delays in highway construction projects in Thailand", International Journal of Project Management, Vol. 17, pp 149159, 1999.

13. Sadi, A. A., Sadiq, A., "Causes of delay in large construction projects", International Journal of Project Management, Vol. 24, pp 349-357, 2006.

14. NIST/SEMATECH e-Handbook of Statistical Methods, http://www.itl.nist.gov/div898/handboo k/, Visited $9^{\text {th }}$ May 2009. 